\title{
Modeling of Anisotropic Inelastic Behavior
}

\author{
D.J. Nikkel, Jr., D.S. Nath, A.A. Brown, J. Casey
}

February 25, 2000

U.S. Department of Energy






\section{DISCLAIMER}

This document was prepared as an account of work sponsored by an agency of the United States Government. Neither the United States Government nor the University of California nor any of their employees, makes any warranty, express or implied, or assumes any legal liability or responsibility for the accuracy, completeness, or usefulness of any information, apparatus, product, or process disclosed, or represents that its use would not infringe privately owned rights. Reference herein to any specific commercial product, process, or service by trade name, trademark, manufacturer, or otherwise, does not necessarily constitute or imply its endorsement, recommendation, or favoring by the United States Government or the University of California. The views and opinions of authors expressed herein do not necessarily state or reflect those of the United States Government or the University of California, and shall not be used for advertising or product endorsement purposes.

Work performed under the auspices of the U. S. Department of Energy by the University of California Lawrence Livermore National Laboratory under Contract W-7405-Eng-48.

This report has been reproduced

directly from the best available copy.

Available to DOE and DOE contractors from the

Office of Scientific and Technical Information

P.O. Box 62, Oak Ridge, TN 37831

Prices available from (423) 576-8401

http://apollo.osti.gov/bridge/

Available to the public from the

National Technical Information Service

U.S. Department of Commerce

5285 Port Royal Rd.,

Springfield, VA 22161

http://www.ntis.gov/

OR

Lawrence Livermore National Laboratory

Technical Information Department's Digital Library

http://www.llnl.gov/tid/Library.html 


\title{
odeling of Anisotropic Inelastic Behavior
}

\author{
Daniel J. Nikkel, Jr. and Deepak S. Nath \\ New Technologies Engineering Division \\ Mechanical Engineering
}

\author{
Arthur A. Brown and James Casey \\ University of California at Berkeley \\ Berkeley, California
}

An experimental capability, developed at Lawrence Livermore National Laboratory (LLNL), is being used to study the yield behavior of elastic-plastic materials. The objective of our research is to develop better constitutive equations for polycrystalline metals. We are experimentally determining the multidimensional yield surface of the material, both in its initial state and as it evolves during large inelastic deformations. These experiments provide a more complete picture of material behavior than can be obtained from traditional unlaxial tests. Experimental results show that actual material response can differ significantly from that predicted by simple idealized models. These results are being used to develop improved constitutive models of anisotropic plasticity for use in continuum computer codes.

\section{Introduction}

At a microstructural level, polycrystalline metals are composed of aggregates of individual crystals, each of which has its own orientation and properties. When subjected to loading, metals initially exhibit reversible deformation, due to the stretching of the lattice. When the loads become sufficlently large, permanent deformations can occur through a number of mechanisms, such as dislocation motion. twinning, or grain boundary sliding. As a consequence of having randomly distributed graln orientations, annealed polycrystalline metals typically exhibit isotroplc behavior with respect to a reference configuration; that is, at a given point in the material, the material response of a specimen in any direction is the same. This includes the elastic behavior and the initial yield behavior. However, signiflcant processing of materials, or even moderate plastic deformations, can cause grains which were inltially randomly oriented to become aligned, resulting in behavior which is anisotropic, where material response in different directions is quite different.

The ability of numerical simulations to predict the behavior of systems involving materials undergoing large deformations is contingent upon having a realistic model of the materlal behavior. Such models must be accurate in the full range of possible loading conditions to which the materials may be subjected. Use of overly simplified models in regimes where they are not well suited can seriously compromise the validity of a simulation. Many problems of engineering interest involve metals undergoing large deformation under multiaxial states of stress and the need for rellable models for these applications can hardly be overemphasized. Experimental data demonstrate that simple models for plasticity commonly used in numerical codes do not accurately predict material behavior under these conditions.

Engineering models of polycrystalline metals generally omit microstructural details and describe the effective macroscopic behavior in terms of a phenomenological continuum model. Vlewed from the macroscopic perspective, the initial material response is path-independent and there is a one-toone correspondence between stress and strain. However, if the deformation or loads become suffclently large, the material begins to exhibit plastic behavior. There is no longer a one-to-one correspondence between stress and strain, the response is dependent on the loading path taken to reach a given state of deformation, and permanent deforma- 
tion remains after external loads are removed. This gives rise to the theoretical Idealization of an elastic-plastic materiąl, and in particular, to the notion of a yleld function denoted by

$$
f\left(s_{k j}, e_{k l}^{p}, \kappa, \ldots\right)=g\left(e_{k l}, e_{k l}^{p}, \kappa, \ldots\right) .
$$

Here, $s_{k l}$ denotes the components of the stress tensor; $e_{k l}$ denotes the components of the strain tensor; $e_{k l}^{p}$ denotes the components of the plastic strain tensor; $\kappa$ is a scalar measure of work hardening; and the ellipses represent other Inelastic state variables which may be present, depending on the complexity of the chosen constitutive theory.

The yleld function is a key ingredient of the constitutive theory of elastic-plastic materials. The condition $f=0$ ( $о г g=0$ ) describes the boundary between stresses (or strains) that result in only elastic behavior, and those which result in inelastic behavior. For fixed values of the inelastic vartables, the yield condition can be interpreted geometrically from the point of view of stress space (or strain space), as a surface which bounds the region in which only elastic behavior occurs (the elastic region). When the loading path intersects the yleld surface and tries to cross it, inelastic behavior occurs and plastic deformation results. The current state never moves outside the yleld surface, but instead the surface is carrled along with it. Typically, the yleld surface changes both in shape and stze as the inelastic deformation increases. Measured yleld surfaces for three of the states along the complex stress path depicted in Fig. 1a are shown in Fig. 1b.

In addition to the yield function, the constitutive theory includes evolution equations for the inelastic varlables durlng loading $(g=0, \hat{g}>0)$. Thus, for the plastic strain, we have

$$
\dot{e}_{k l}^{p}=\rho_{k l}\left(e_{m n}, e_{m n}^{p}, \kappa, \ldots\right) \hat{g}, \quad \hat{g} \equiv \frac{\partial g}{\partial e_{m n}} \dot{e}_{m n} .
$$

Here $\rho_{k l}$ is a constitutive response function that is independent of the rates of stress or strain. For a broad class of materials, under a physically reasonable assumption regarding work in closed cycles in strain space, $\rho_{k l}$ can be replaced with the product of a scalar function and the normal to the yield surface in stress space, thus requiring the specification of only one additional scalar response function. For special classes of materials, this scalar function is determined from the yield function and hardening and does not require an independent specification.

Most plasticity models implemented Into numerical codes for metals use a yleld criterion which corresponds to a fixed shape of the yleld surface (for example, elliptical in the case of the Mises yield criterion). What distingulshes different models is how the yield surface evolves (for example, it may translate rigidly, or alternatively change its size while maintaining its shape, or follow some combination of these simple hardening laws). Many simulations are run with a model that assumes an elliptic yleld surface of fixed aspect ratio that only changes in size due to hardening. While the initlal yield surface of isotropic materials may be represented reasonably well by an ellipse, subsequent to even moderate plastic deformation, the shape of the yleld surface in real materials can change significantly (F1g. 1b). For this reason, simple representations of the yleld function will be satisfactory only under very restrictive loading conditions (such as monotonic or uniaxial), and are inadequate for general multiaxla! loading conditions, especlally when loads can reverse and change direction during the history of loading.

In view of these considerations, and motivated by the fact that the vast majority of avallable experimental data on polycrystalline metals are for uniaxial (and generally monotonic) loading, our group developed an experimental capability to map out the yield surface at various fixed states of large inelastic deformation under multiaxial loading. By determining the yield surfaces on a single specimen at multiple fixed states, the evolution of the yield surface during plastic deformation can be observed. These data provide the basis for developing improved constitutive equations for phenomenological descriptions of polycrystalline metals.

\section{Progress}

This project is a combination of a program of novel experiments characterizing inelastic material behavior together with an effort to develop better material models for implementation into numerical analysis codes. The primary approach has been to obtain improved experimental data for the macroscopic response as a guide to the development of better phenomenological models. During FY-99, we have further refined the experimental procedures developed in previous years, and have obtained some important new data.

In addition to this direct macroscopic approach. we have begun to examlne the alternative strategy of incorporating information from lower length scales where explicit consideration is taken of material microstructure, and we have also begun to explore how this mesoscale descriptlon can be homogenized to obtaln improved macroscopic models. 
Further, work on general issues related to rumerical implementation of anisotroplc plasticity rnodels has been pursued, in the context of both purely Lagrangian and arbitrary Lagrangian-Eulerian (ALE) formulations.

\section{Experiments}

The experimental portion of this project involves determination of the yield surface under multiaxial states of loading, using thin-walled tension-torsion specimens with a 2-in. inside diameter. The experimental determination of the yleld surface of the material is carried out by loading a specimen under multiaxial conditions and probing until the point of yleld is reached, then backing off and probing in a different direction in stress space (and in strain space) untll the next yjeld point is found. This process is repeated until the entire surface is mapped out. The sensitive nature of the measurements being made requires careful attention to the Issues of specimen design and preparation, experimental methodology, and interpretation of the data. The general description of the experiments and the difficulty in carrying out these measurements have been discussed previously, ${ }^{2.3}$ and this year a comprehensive description of the experimental procedure has been compiled.

Ideally, a measured yleld surface represents the boundary between elastic and inelastic behavior at a given elastic-plastic state. As a practical matter, the identification of the yield point requires loading somewhat beyond the elastic region so that the inelastic behavior becomes evident. The procedure which has been developed can detect yield without producing a plastic strain much greater than $5 \mathrm{x}$ $10^{-6}$ ( $5 \mu$-strain), and yleld surfaces can be obtained for multiple elastic-plastic states from a single specimen. It is clear from the data that the yield surfaces determined from multaxlal loading tests are strongly dependent on the method used to Identify the yleld point. Many different definitions of the yleld point are possible; these vary in both experimental complexity and in the amount of plastic deformation that is induced during the determination of yield at a given point. The measured yleld surfaces can vary from appearing roughly isotroplc when a coarse large off-set or back-extrapolation method is used, to clearly exhibiting materlal anisotropy when a small off-set definition of yield is used (Fig. 1b). The definition of yleld point is related to the idealized way in which the theoretical model represents real material behavior. These issues are discussed more fully elsewhere. ${ }^{4}$ After Investlgating various alternatives, we adopted a $5 \mu$-strain offset definithon of yield as the most meaningful for our current interests.

In addition to generating data from the measurement of yield surfaces, we are also exploring the fundamental question as to the proper definition of plastic strain in the context of large inelastic deformations. ${ }^{5,6}$ When yleld surfaces have moved so that they no longer enclose the origin in stress space (for example, yield surfaces D1 and D2 in F1g. 1b), the material cannot be unloaded to zero stress without causing new plastic deformations.

The traditional way of defining plastic strain is to Identify it with the residual strain remaining when the load is removed. This definition arose intuitively from consideration of unlaxlal tests with small deformation, but it is clearly inadequate in the situation of more general states of loading where the yleld surface no longer encloses the origin in stress space. Plastic strain is not among the set of kinematic variables that come from classical continuum mechanics. Since it is a primitive variable in the constitutive theory, one must be able to identify it unambiguously for the theory to be meaningfully predictive and not simply a sophisticated curve-fit.

Previously, an experimental methodology was proposed for verifying the validity of our prescription for Identifying plastic strain, in cases where the origin lies outside the stress space yield surface. It is defined as the point in strain space corresponding to the point on the yield surface in stress space closest to the origin. ${ }^{5.6}$ This method exploited the property from $\mathbf{E q} .2$ that the direction of the increment in plastic strain is independent of the size and direction of an applied increment in stress or strain. By comparing the directions of the plastic strain increment for two different loading directions ortginating from the same state, the prescription can be verifled. The high precision necessary to be able to make the measurements required for this verificatlon was a driving force governing the refinement of experimental procedures. Three different verifications (requiring the determination of six distinct yield surfaces) have been completed which do in fact validate this prescription for identifying plastic strain.

\section{Characterization of Experimental Results}

One consistent observation in the experimental data with a $5 \mu$-strain off-set definition of yield (such as In Fig. 1b) is a distortion of the shape of the yield surface after moderate plastic deformation when loading away from the origin. The initial yield 
surface is close to elliptical in shape. For subsequent yield surfaces, the side away from the loading point (and closest to the orlgin) tends to flatten, while it tends to elongate near the loading point, resulting in a D-shaped surface. There are classical closed curves, such as the follum, the piriform, and the pear-shaped quadric, that are somewhat Dshaped. ${ }^{7}$ However, after some effort it was found not possible to use these functions to represent the data in a robust manner. An alternative approach to using a single analytical function to represent the yield surface in two dimensions is to approximate it with a collection of smooth intersecting segments. As a curve-fitting scheme this approach is capable of matching a given set of data with any desired degree of accuracy, but such a representation provides little physical insight towards the development of improved models. Moreover, describing yield surface evolution in a general way becomes problematic, and it also presents difficulties in terms of numerical implementation.

To characterize the data, and to give some direction to the development of improved models, "best fits" to the data were performed with polynomial functions representing closed curves. Even for quadratic polynomials this is a nontrivial exercise. In the usual routine task of fitting a function to discrete $x-y$ data, an error function is defined and the unknown coefficients are determined by minimizing the error. The resulting system of equations is linear and a unlque solution is guaranteed.

For the problem at hand, however, the data pairs $\left(x_{1}, y_{1}\right)$ cannot be approximated by an explicit functhon of the form $y=f(x)$; rather they must be repre- sented by Implicit functions of the form $f(x, y)=0$. To fit an Implicit function to the data, an error function is defined as usual, but the system of equations that must be solved to determine the unknown coefflclents is highly nonlinear and there is no guarantee of unlqueness as in the linear case. Solving the system of nonlinear equations numerically is a complex undertaking requiring sophisticated solution techniques.

Quadratic fits to all the data sets were obtained by using a package for orthogonal distance regression, ODRPACK, which is publicly avallable from NIST. The program finds the parameters that minimize the sum of the squared weighted orthogonal distances from a set of observations to the curve or surface determined by the parameters. Thls procedure provided a method of characterizing the data in terms of change in position, size, and orlentation of subsequent yield surfaces. Results of the data reduction for various measured yleld surfaces are shown in Table 1. A second-order polynomial is sufficient for gauging the size, location, and some sense of the "ortentation" of the yield surface, but it cannot adequately represent features such as relative elongation and flattening of the yield surface. Higher order function fits could likely provide better representations of the D-shaped data curves, but ODRPACK was unable give rellable fits in a unique, robust manner.

\section{Numerical Modeling}

The Mises yleld condition, which is a quadratic polynomial in the deviatoric stress components, is known to agree well with experimental data on

Table 1. Characteristics of yield surface dato obtained from quadratic fits. The yield surface designation comes from a specimen identification letter and a state number.

\begin{tabular}{|c|c|c|c|c|c|c|c|c|}
\hline $\begin{array}{l}\text { Yleld } \\
\text { surface }\end{array}$ & $\begin{array}{l}\text { Offsel } \\
\text { Def. (11* } \\
\text { strain }\end{array}$ & $\begin{array}{c}e q i \\
(1+\cdot) \\
\text { strain) }\end{array}$ & $\begin{array}{l}e p_{2} \\
(11 \cdot \\
\text { strain) }\end{array}$ & $\begin{array}{c}\text { Center } \\
\text { (psi) }\end{array}$ & $\begin{array}{l}\text { Orlentation } \\
\text { angle } \\
\left({ }^{\circ}\right)\end{array}$ & $\begin{array}{c}\text { Subaxis } \\
1 \\
\text { (psi) }\end{array}$ & $\begin{array}{l}\text { Subaxis } \\
2 \\
\text { (psi) }\end{array}$ & $\begin{array}{c}\text { Aspect } \\
\text { ratlo }\end{array}$ \\
\hline A1 & 15 & & 0 & $(857,-57)$ & 29.8 & 1250 & 1460 & 0.86 \\
\hline A2 & 15 & 8690 & 7128 & $(871,947)$ & -16.3 & 3000 & 1380 & 2.17 \\
\hline B0 & 1 & 0 & 0 & $(-87,94)$ & 3.91 & 1770 & 1060 & 1.67 \\
\hline B1 & 1 & 1 & -17 & $(-11,-263)$ & 2.23 & 1840 & 890 & 2.07 \\
\hline $\mathrm{B} 2$ & 1 & 92 & -2055 & $(37,-1809)$ & -1.12 & 1550 & 370 & 4.19 \\
\hline C1 & 1 & -4578 & 102 & $(-3425,114)$ & 24.7 & 770 & 1170 & 0.66 \\
\hline $\mathrm{C} 2$ & 1 & & 234 & $(-3713,82.4)$ & 40.4 & 640 & 1050 & 0.61 \\
\hline D1 & 5 & 5 & -2020 & $(-209,-1698)$ & -7.2 & 2230 & 650 & 3.43 \\
\hline D2 & 5 & 30 & -2100 & $(80,-1698)$ & -0.9 & 2330 & 750 & 3.11 \\
\hline D4 & 5 & 30 & -2010 & $(84,-1230)$ & -3.3 & 2610 & 770 & 3.39 \\
\hline D10 & 5 & 1030 & -3660 & $(1250,-1918)$ & 14.0 & 2380 & 670 & 3.55 \\
\hline D12 & 5 & & -3560 & $(1145,-1459)$ & 26.0 & 2570 & 1070 & 2.40 \\
\hline
\end{tabular}


annealed (isotropic) polycrystalline metals, and it also has a physically appealing interpretation in terms of distortion energy. For anisotropic materials, the most general quadratic yield function representing a smooth initial yleld surface which reduces to the Mises yield function in the special case of isotropic materials is of the form ${ }^{9}$

$$
f=B_{k i m n} s_{k j} s_{m n}-K^{2}
$$

where due to symmetries the coefficients $B_{k I m n}$, have 21 independent components. If, as is commonly done, the further assumption is made that the yield behavior is independent of the mean stress (pressure), then the stress tensor in Eq. 3 can be replaced by its deviatoric part and the coefficient tensor can be replaced by a reduced tensor which has 15 independent coefficients. As mentioned prevlously, a quadratic representation of the yleld surface can reasonably capture its location, size, and a sense of the orientation observed in real materials, but it does not capture the distortion of the yield surface from elliptical to D-shaped. Nevertheless, Eq. 3 is much more general than the Mises yleld function, and it contains as special cases other anisotroplc yield models which have been implemented into LLNL codes.

An anisotropic plasticity model with the yield function in Eq. 3 was implemented into the parallel version of the code ALE3D. Figure 3 shows a Lagrangian numerical simulation of a Taylor impact test using an anisotropic tantalum cylindrical projectile. The predicted ovaling of the impact footprint is in agreement with experimental data.

Since a basic feature of anisotroplc behavior is that the response depends on the materlal direction, it Is necessary to track materlal directions during deformation. While this is a straightforward issue within a Lagranglan formulation, implementation of anisotropic plasticity models in the context of an ALE formulation is complicated by the fact that nodes of a mesh are not material points, and the element edges are not material curves. An alternative approach must be used to keep track of material directlons. Material direction vectors $m_{l}$ can be stored as element-based variables, and can then be updated during the Lagrangian step according to

$$
\dot{m}_{i}=\left(L_{i j}-\left(L_{k l} m_{k} m_{i}\right) \delta_{i j}\right) m_{j}
$$

where $L_{l /}$ are the components of the velocity gradient tensor. These element-based quantitles can then be updated as other history varlables during the advection step. There are increased memory storage costs associated with modeling anisotropic plasticity. Along with storing the material direction vectors and any additional constitutive variables, properly invariant formulations of anisotropic models also require storing additional kinematical quantities such as the rotation and stretch tensors.

\section{Alternative Approaches Using Mesoscale Homogenization}

The approach described earlier seeks to develop a macroscopic phenomenological model directly from measurements of the macroscoplc inelastic behavior. An alternative strategy is to examine the governing processes in terms of microphysical behavior at lower length scales, and then to deduce a model for the effective macroscopic behavior through an appropriate averaging, or homogenization, procedure.

Working toward a theoretical approach to homogenization, using a variational principle, and in the context of strain gradient сгystal plasticity, we developed a new upper bound for the effectlve yield surface of a polycrystal. ${ }^{11}$ This procedure uses oneand two-point correlation functions of the orlentation distribution. This bound demonstrates a grain slze effect via its dependence on the polycrystal's spatial and orientation distribution statistics. It can be shown that this bound almost always improves upon the Taylor model bound.

It is also possible to approach the homogenization from the point of view of numerical simulations using a so-called virtual test sample. A representative volume element of material can be modeled in which individual grains are explicitly resolved, and represented by a single-crystal plasticity model. Such a numerical test sample can be used to simulate the macroscopic behavior under a wlde varlety of loading conditions, guiding the development of a macroscoplc phenomenological model. In preparation for this approach, detalled orientation imaging microscope (OIM) scans have been made at regular depths through a carefully prepared tantalum speclmen, mapping out the orlentation of individual grains (Fig. 4). From this detalled database a 3-D numerlcal model can be generated which accurately represents the real microstructure of the materlal. This numerical model can then be subjected to a variety of loading conditions, and the effective macroscopic behavior predicted. The yleld surface data that has been generated can be used as a validation check for both theoretical and numerical homogenization methodologies. 


\section{Future Work}

This project has produced an experimental capability that provides multiaxial data, which can be used to develop and validate advanced constitutlve models. We have also established a solid framework from which to pursue numerical developments of anisotropic plasticity. From this foundation, further developments will continue, focusing on the development of improved material models for ASCI codes.

\section{Acknowledgments}

Contributions to this project by J. Casey result from work supported by a grant from the Solid Mechanics Program of the National Sclence Foundation. Part of the support for A. Brown's work, and materlal used during the development of the experimental procedure, were also provided through this grant.

\section{References}

1. P. M. Naghdi (1990), "A critical review of the state of finite plasticity." J. Appl. Math. Phys. (ZAMP), 41, pp. $315-394$.

2. D. J. Nikkel, A. A. Brown, and J. Casey (1998), "Evolution of anlsotropic yield behavlor," Engineering Research. Development and Technology, Lax'rence Livermore National Laboratory, Livermore, California (UCRL53868-97), pp. 5-1-5-5.

3. D. J. Nikkel, A. A. Brown, and J. Casey (1999), "Modeling of an!sotroplc inelastic behavior." Englneering Reseanch, Development and Technology, Lawrence Livermore National Laboratory, Livermore. Callfornia (UCRL 53868-98), pp. 6-1-6-6.

4. A. A. Brown, and D. J. Nikkel (1999), "Experimental methodology for yield surface measurement under blaxlal states of stress," Lawrence Llvermore National Laboratory. Livermone, Californla, in preparation.
5. J. Casey and P. M. Naghdl (1992), "A prescription for the identification of finite plastic strain," Int. $J$. Engng. Scl. 30. pp. 1257-78.

6. J. Casey, and P. M. Naghdi (1992), "On the Identification of plastic strain at finite deformation," in Defects and Anelasticity in the Characterization of Crystalline Solids, L. M. Brock, ed., ASME AMD Vol. 148. pp. 11-33.

7. J. D. Lawrence (1972). A Catalog of Special Plane Curves, Dover, New York.

8. P. T. Boggs. R. H. Byrd, J. E. Rogers, and R. B. Schnabel (1992), "User's reference guide for ODRPACK verslon 2.01: software for weighted orthogonal distance regression," U. S. Department of Commerce, (NISTIR 92-4834).

9. A. E. Green and P. M. Naghdl (1965), “A general theory of an elastic-plastic continuum," Arch. Rat. Mech. Anal., 18, pp. 251-281.

10. P. J. Maudlin, J. F. Bingert, J. W. House, and S. R. Chen (1999). "On the modeling of the Taylor cylinder Impact test for orthotropic textured materials: experiments and simulations," Int. J. Plasticity, 15. pp. 139-166.

11. D. D. Sam and V. P. Smyshlyaev (1999), "Grain size effect for the polycrystal's yield surface in strain gradient plasticity," in preparatjon.

Figure 1. (a) Imposed sequence of loading states for yield surfoce measurement on a single specimen, identified as " $D$ " in Table 1 . (b) Measured points on yield surfaces in 2-D stress space from a single 1100 aluminum specimen subjected to the loading states in Fig. 1a. For clarity, only the surfoces measured at load states 0,1 , and 2 in Fig. 1 a have been shown. The subsequent yield surfaces show significant deviation from an idealized ellipse even though the strains involved are moderately small.

Figure 2. Second-order polynomial fits to yield surface data. Quadratic functions can capture the trends in size, location and some sense of orientation, but provide no characterization of the distortion into the observed D-shapes.

Figure 3. Numerical simulation of a Taylor impact test of an anisotropic tantalum circular cylinder exhibiting ovaling of the impact footprint. For isotropic material properties, the cylinder would expand axisymmetrically at the impacting end. The calculation agrees with experimental results.

Figure 4. Orientation Imaging Microscope scan of one plane of a well-characterized tantalum polycrystal. The shading indicates particular crystal orientation. Similar scans, at a sampling resolution of $4.5 \mu \mathrm{m}$, have been made at 47 planes through the sample. From these data a 3-D numerical model can be constructed representing the microstructure. 


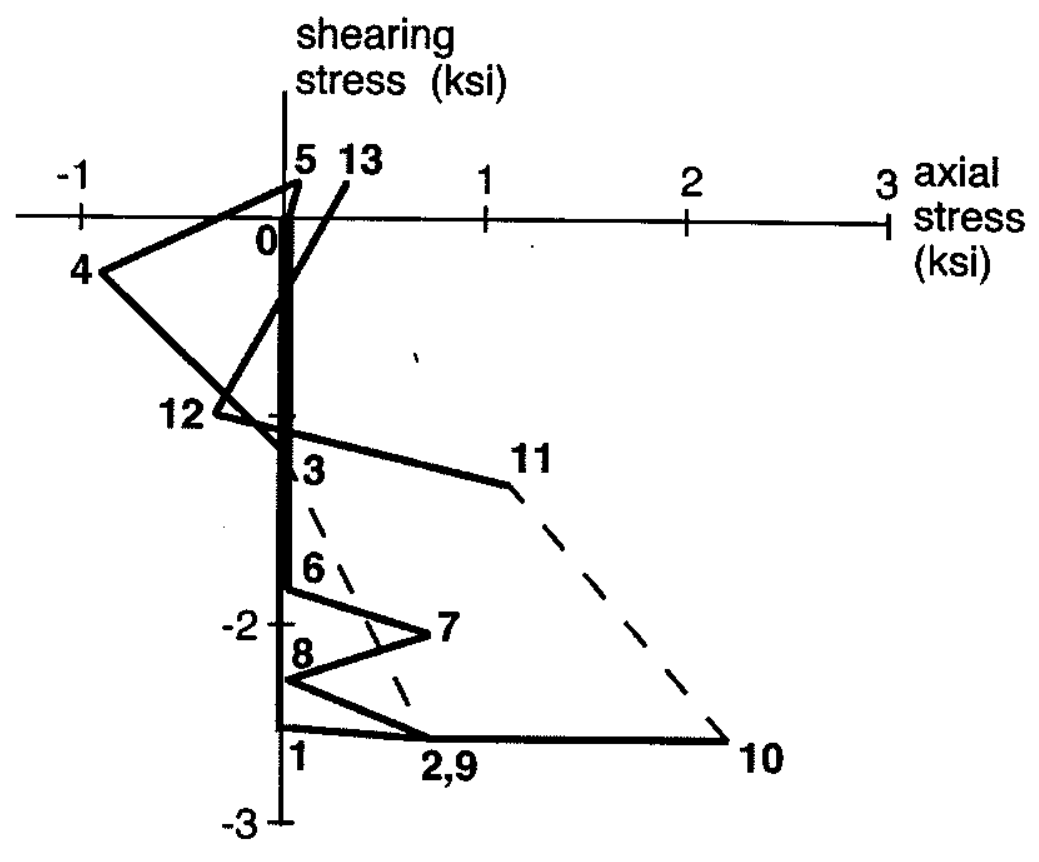

Figure Ia 


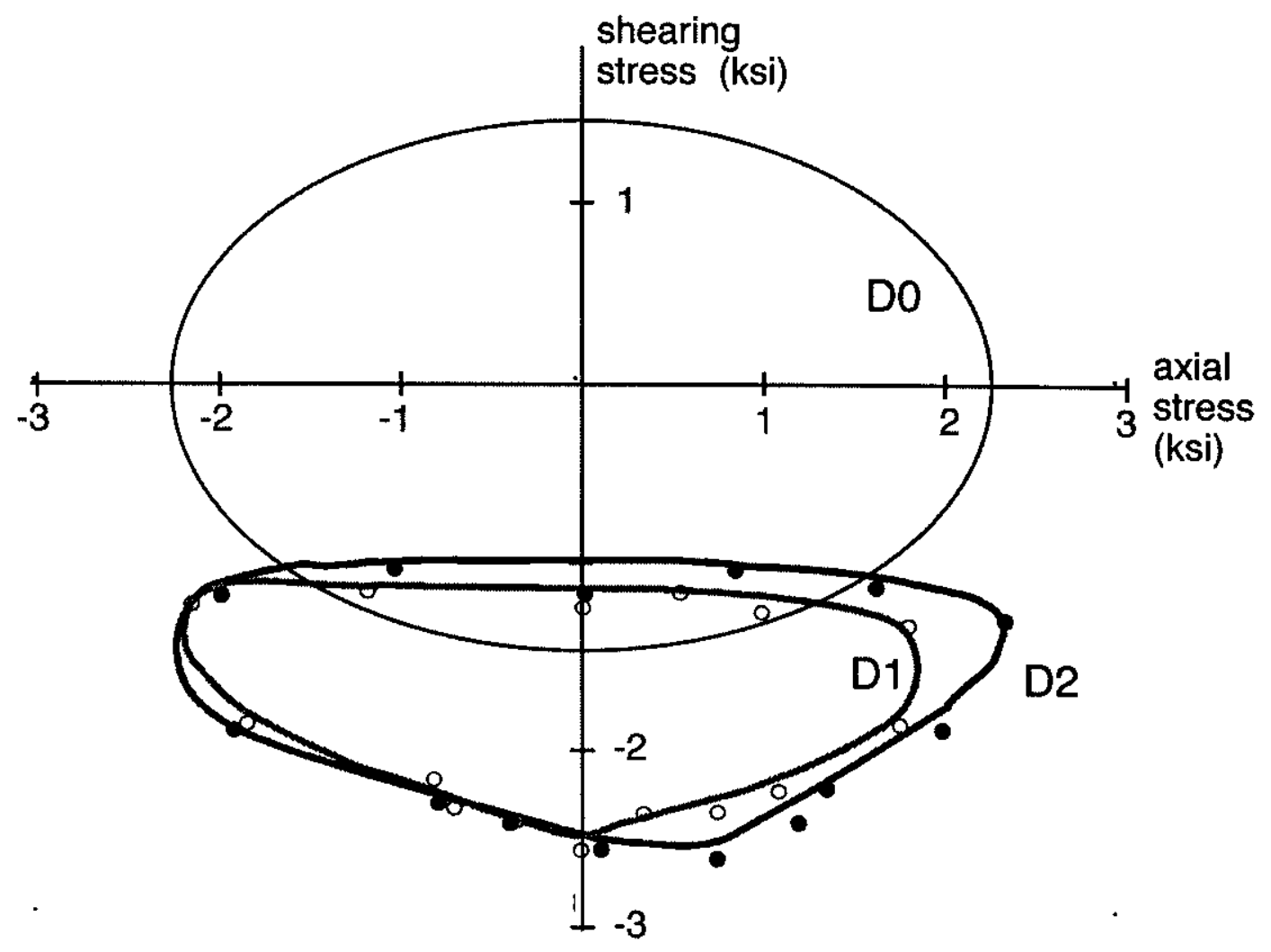

Figure $1 b$ 


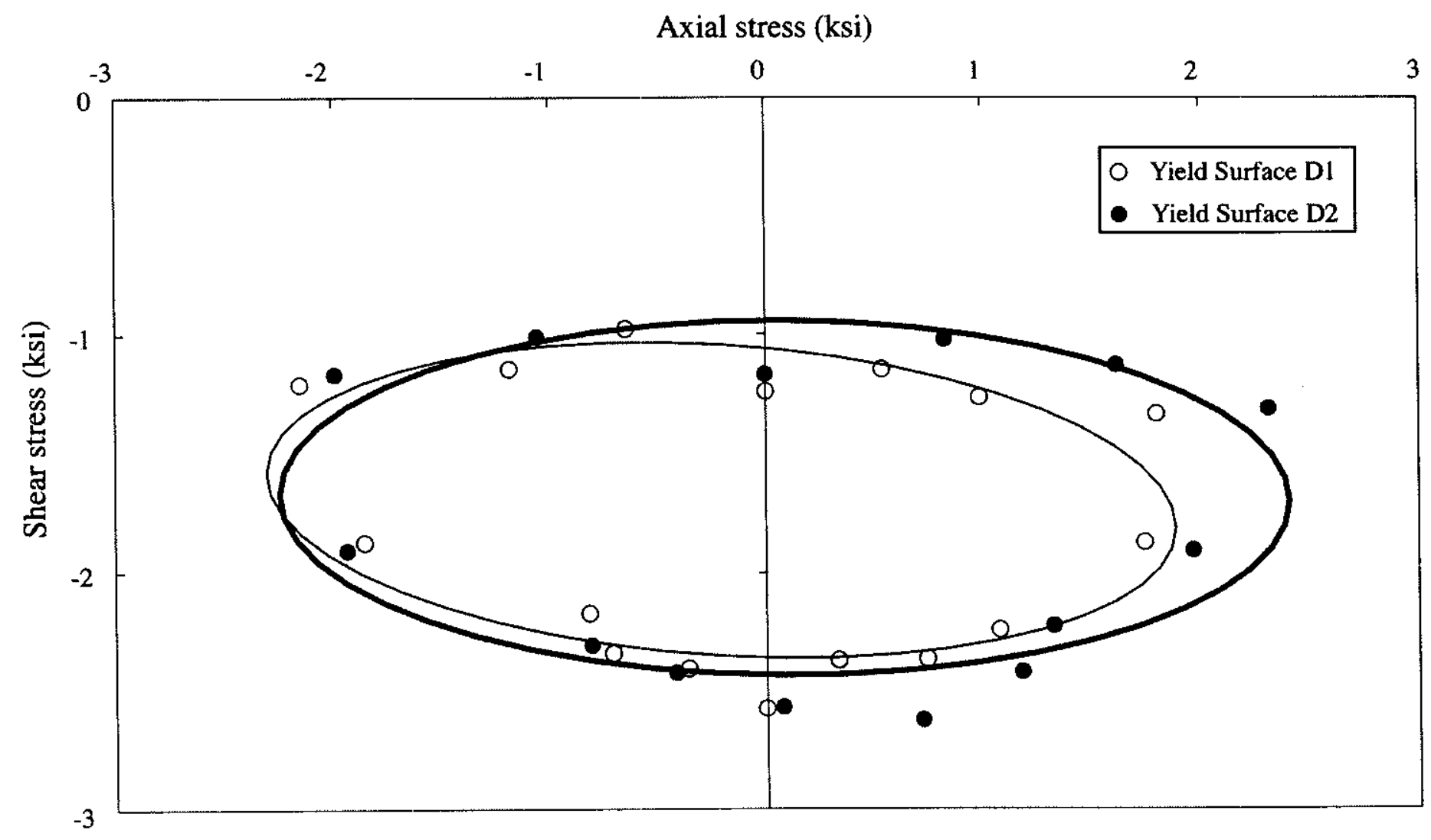

Figure 2 


$$
6
$$




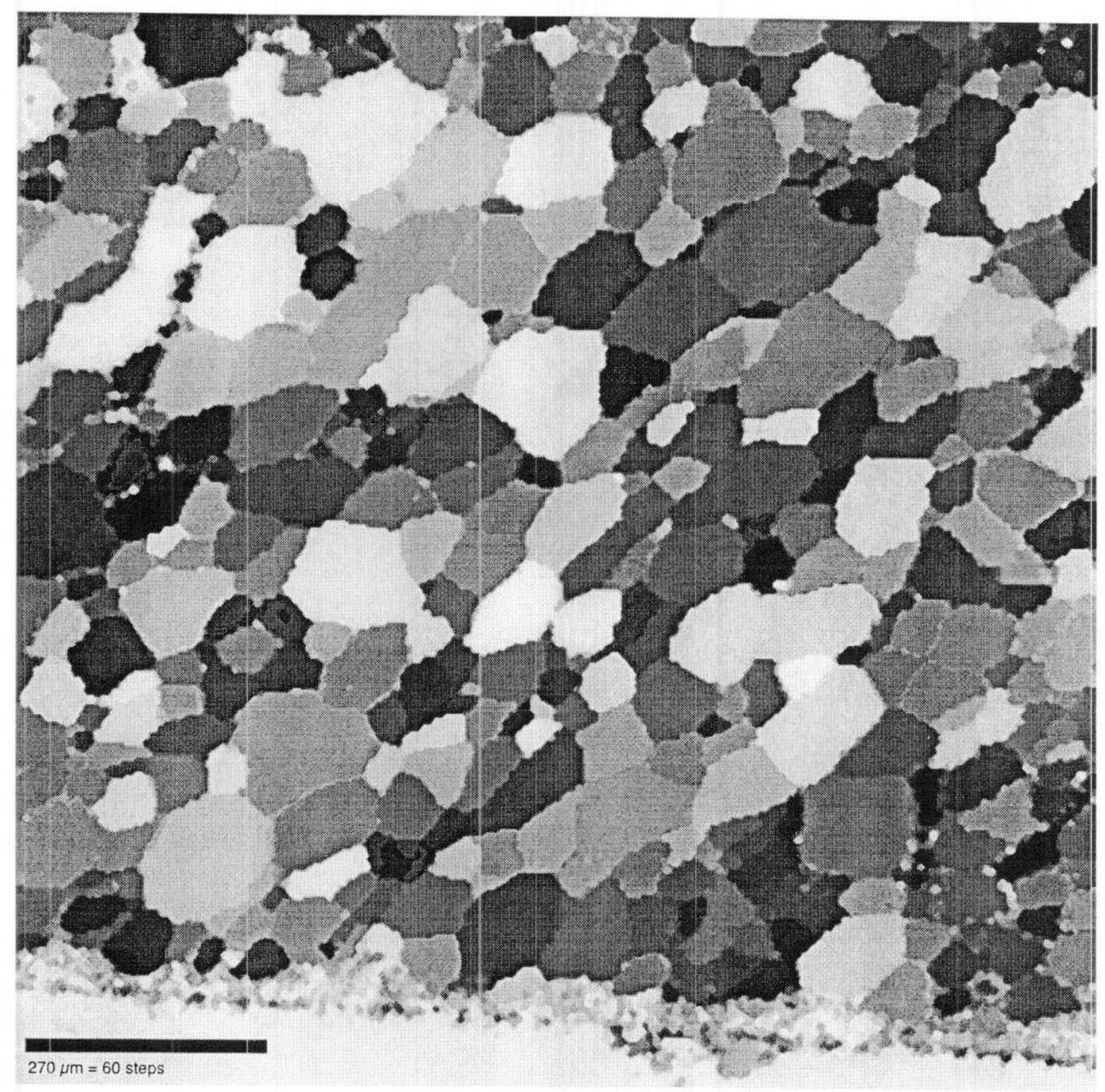

Figure 4 